\title{
INFLUÊNCIA DO FOTOPERÍODO EMERAL SOBRE CARCTERISTICAS BROMATOLÓGICAS DA CARCAÇA DE JUVENIS DE TAMBAQUI (Colossoma macropomum)
}

\author{
Pedro Pierro Mendonça ${ }^{1}$, Monique Virães Barbosa dos Santos², Manuel Vazquez Vidal Junior ${ }^{3}$, \\ DALCiO RicARDo DE ANDRADE ${ }^{4}$
}

1 - Doutorando da Universidade Estadual do Norte Fluminense Darcy Ribeiro -

2 - Fundação Instituto de Pesca do Estado do Rio de Janeiro

3 - Professor, DS, LZNA/UENF

4 - Professor, DS, LZNA/UENF - dalcio@uenf.br

\section{RESUMO}

O objetivo do presente estudo foi avaliar a influência do fotoperíodo emeral na composição bromatológica da carcaça de juvenis de tambaqui (Colossoma macropoтum). $\mathrm{O}$ experimento foi realizado utilizando 190 peixes com peso médio de $11,01 \pm 2,08 \mathrm{~g}$ e comprimento total de $7,8 \pm 0,18 \mathrm{~cm}$, acondicionados em dezesseis aquários de 56 litros com renovação de 40 vezes o volume ao dia. A temperatura da água foi mantida em $29,1 \pm 0,41^{\circ} \mathrm{C}$ e a densidade de estocagem foi equivalente a $2,75 \mathrm{~g} / \mathrm{L}$, sendo que todos os aquários possuíam aeração constante. Os fotoperíodos emerais foram mantidos com auxílio de timers. Foram utilizados os seguintes tratamentos: T1 $=6$ horas de luz, T2 $=12$ horas de luz, T3 = 18 horas de luz e T4 = 24 horas de luz, com quatro repetições cada. Os juvenis foram alimentados duas vezes ao dia, com ração comercial extrusada ( $28 \%$ de proteína bruta). Ao iniciar o experimento, com 32 dias e ao final do período experimental, foram feitas análises da composição bromatológica das carcaças evisceradas e descamadas, para avaliação da proteína bruta, estrato etéreo, matéria mineral e extrato não nitrogenado na matéria seca e na matéria natural. A análise estatística das variáveis foi realizada com auxílio do aplicativo SAEG, versão 9.1, para realização de análise de variância, regressões e correlações de Pearson. Não foi observado efeito dos fotoperíodos emerais $(p<0,05)$ nas variáveis.

PALAVRAS-CHAVE: Aquicultura; bioclimatologia; peixes nativos

\section{INFLUENCE OF AHEMERAL PHOTOPERIOD ON BROMATOLOGICAL CHARACTERISTICS OF CARCASSES OF TAMBAQUI (Colossoma macropomum) JUVENILES}

The aim of this study was to evaluate the influence of ahemeral photoperiod on the chemical composition of the carcasses of tambaqui (Colossoma macropomum). The experiment was conducted using 190 fish with average weight of $11.01 \pm 2.08 \mathrm{~g}$ and total lenght of $7.8 \pm 0.18 \mathrm{~cm}$, stored in sixteen bowls of 56 liters of water with daily renewal of 40-times volume. The water temperarature was maintained at $29.1 \pm 0.41^{\circ} \mathrm{C}$ and the stocking rate was equivalent to $2.75 \mathrm{~g} / \mathrm{L}$. All tanks had constant aeration. Ahemeral photoperiods were maintained with the aid of timers. The following treatments were used: T1 $=6$ hours of 
light, T2 $=12$ hours of light, T3= 18 hours of light and $\mathrm{T} 4=24$ hours of light with four replications each. The juveniles were fed twice a day with commercial extruded feed ( $28 \%$ crude protein). The experiment lasted 64 days and the chemical composition of eviscerated and shedded carcasses were analysed at the beginning, at 32 days and at the end of it for the evaluation of crude protein, ether

KEYWORDS: Acquaculture; Bioclimatology; Native fish.

\section{INTRODUÇÃO}

O volume pescado proveniente da aquicultura vem apresentando um crescimento contínuo nos últimos 10 anos enquanto a atividade extrativista durante este mesmo período de tempo apresentou queda na sua produção (FAO, 2007).

A aquicultura, por seu crescente aporte na produção mundial de pescado, surge como alternativa para aumentar a produção de alimentos. HUSS (1998), previu que nos próximos anos haverá um aumento na demanda de pescado nos países em desenvolvimento por ser uma alternativa de alimento de alto valor nutritivo e possuir relativamente baixos teores de gordura e uma proteína de alta digestibilidade.

Em geral, a composição química do pescado varia entre peixes da mesma espécie e entre diferentes partes do mesmo peixe. Essas variações são devidas a fatores como época do ano, alimentação, diferença entre sexos e características genéticas, entre outras causas (GURGEL \& FREITAS, 1972; CONTRERAS-GUZMÁN, 1994; OGAWA \& MAIA, 1999; KUBTIZA, 2000; GARDUÑO-LUGO et al., 2003).

Dentre os fatores relacionados ao ambiente de cultivo, o fotoperíodo emeral influencia o desenvolvimento e a sobrevivência em diferentes fases ontogênicas, pois a luz auxilia tanto na estratégia alimentar como no estímulo a outras atividades metabólicas de várias espécies de peixes (REYNALTETATAJE, 2002). O fotoperíodo corresponde a um dos diversos estímulos ambientais e está relacionado à duração do tempo de luz ao longo de um dia (BEZERRA et al., 2008). A intensidade e o aumento desse tempo de luz se modificam com as estações do ano e o clima da região (BROMAGE et al., 2001).

Sabe-se que o fotoperíodo influencia no crescimento e no ciclo reprodutivo da tilápia (BROMA- extract, ash and non nitrogenous extract in dry matter and in natural matter. Statistical analysis of variables was performed with the aid of SAEG application, version 9.1. For performing analysis of variance, Pearson correlations and regressions were used. There was no effect of ahemeral photoperiods $(\mathrm{p}<0.05)$ in variables.

GE et al., 2001). Contudo, existem poucas informações sobre os efeitos desses fatores ambientais na composição bromatológica de peixes tropicais como o tambaqui, nas diferentes fases de produção dessa espécie.

O conhecimento da composição bromatológica dos peixes é necessário para que sua introdução no mercado seja mais efetiva, possibilitando a competição com outras fontes protéicas de origem animal amplamente utilizadas, como a carne bovina, suína e de aves (BELLO \& RIVAS, 1992). Esse conhecimento também permitirá avaliar a eficiência da transferência de nutrientes do alimento para o peixe e os manejos mais adequados para melhor composição das carcaças.

As análises dos parâmetros bromatológicos em peixes confinados têm sido largamente utilizadas para avaliar o estado de saúde de animais sob cultivo intensivo (TAVARES-DIAS et al., 2001), podendo auxiliar no diagnóstico, prevenção e controle de patologias associadas ao estresse (CHAGAS et al., 2002).

Objetivou-se com este trabalho avaliar a existência de efeito ou não, do fotoperíodo emeral sobre a composição bromatológica da carcaça de juvenis de tambaqui.

\section{MATERIAL E MÉTODOS}

O experimento foi realizado no Setor de Aquicultura da Universidade Estadual do Norte Fluminense (UENF/RJ), situado no Colégio Agrícola Estadual Antônio Sarlo em Campos dos Goytacazes - RJ, durante o período de quatro de maio a sete de julho de 2006, totalizando 64 dias de experimento.

Foram utilizados 190 juvenis de tambaqui (Colossoma macropomum) provenientes do Projeto Piabanha localizado em Itaocara, município do Rio de Janeiro, com idade aproximada de 60 dias e peso inicial de $11,01 \pm 2,08 \mathrm{~g}$, distribuídos em 16 aquários 
com medidas aproximadas de 30 x 60 x $50 \mathrm{~cm}$ (largura $\mathrm{x}$ comprimento $\mathrm{x}$ altura), utilizando um volume total de 56 litros e volume útil de $40 \mathrm{~L}$ cada, com densidade inicial equivalente a $2,75 \mathrm{~g} / \mathrm{L}$ por aquário. Ao iniciar o experimento, 30 peixes do lote inicial foram abatidos para análise bromatológica das carcaças.

Os juvenis passaram por um processo de adaptação à rotina experimental de 12 dias, sendo esse período dividido em sete dias no laboratório de aquicultura e cinco dias dentro dos aquários experimentais, onde foi feita a reposição de qualquer animal que por razoes distintas apresentasse comportamento irregular, que pudesse comprometer os dados finais do experimento. Após inicio do período experimental nenhum juvenil foi reposto nas unidades experimentais. Os peixes foram alimentados duas vezes ao dia.

$\mathrm{O}$ aquário mais os dez juvenis de tambaqui, juntos, formavam uma unidade experimental. As unidades experimentais foram distribuídas em um delineamento inteiramente casualizado, com quatro tratamentos, e cada tratamento com quatro repetições, totalizando 16 unidades experimentais. As mesmas foram isoladas de qualquer tipo de iluminação que não fosse proveniente dos seus respectivos tratamentos, através de lona plástica preta para evitar a incidência de luz durante o período de escuro de cada tratamento, garantindo com isso que o fornecimento de luz só fosse feito durante os períodos estipulados para cada tratamento.

Foram mensurados os parâmetros oxigênio dissolvido $\mathrm{mg} / \mathrm{L}, \mathrm{pH}$, temperatura ${ }^{\circ} \mathrm{C}$, condutividade elétrica $\mu \mathrm{S}$ e intensidade de luz em $\mu \mathrm{mol} \mathrm{m} \mathrm{m}^{-2} \mathrm{~s}^{-1}$, sempre após as refeições feitas às 8:20 e às 13:20 horas. Os níveis de oxigenação foram mantidos com auxilio de aeradores e mensurados através de um oxímetro. $\mathrm{O} \mathrm{pH}$, a temperatura, a condutividade elétrica e a intensidade luminosa foram medidos, respectivamente, por meio de peagâmetro, termômetro digital, condutivímetro digital e medidor de fotometria digital.

O sistema utilizado durante o experimento foi do tipo recirculação fechada e contínua, contendo uma caixa para filtragem da água (através de processos físicos e biológicos), uma caixa depósito (onde a água foi mantida para retorno às unidades experimentais), bombas submersas para retorno da água do sistema e dois termostatos de $300 \mathrm{~W}$ para a manutenção da temperatura durante o experimento.

Os sistemas possuíam abastecimento e escoamento da água com uma renovação de 40 vezes o volume total utilizado nos aquário por dia. $\mathrm{O}$ fluxo da água foi constante visando manter elevado o teor de oxigênio, eliminar as fezes e evitar a formação de plâncton.

O manejo alimentar foi realizado utilizando uma ração comercial contendo $28 \%$ de $\mathrm{PB}$ e 3.100 $\mathrm{kcal}$ de $\mathrm{ED} / \mathrm{kg}$. A ração foi fornecida à vontade, às 8:20 e às 13:20 horas. Após 15 minutos as sobras eram retiradas. Nos aquários onde não havia sobra, a alimentação foi repetida até que os mesmos apresentassem sobras.

Foram feitas coletas de sangue para mensuração de glicose sanguínea com o objetivo de verificar indicadores de estresse nos peixes e análises bromatológicas das carcaças evisceradas e escamadas, para verificar possível efeito causado pelos diferentes fotoperíodos na composição bromatológica das carcaças de 30 juvenis de tambaqui.

As coletas de sangue foram realizadas em três momentos: no início do experimento, com 32 dias e ao término do mesmo (64 dias). Dos cinco peixes que foram retirados aos 32 e aos 64 dias de cada unidade experimental para análise bromatologica, três foram utilizados para coleta de sangue, a qual foi realizada com auxilio de seringas de 3,0 $\mathrm{mL}$ com agulhas 25/7. O conjunto de seringas e agulhas foi lavado com fluoreto de potássio com o objetivo de evitar a coagulação e a glicólise sanguínea.

Os peixes foram anestesiados com uma solução contendo $65 \mathrm{ppm}$ de eugenol. A coleta de sangue foi feita poe meio de punção da veia caudal, retirando um volume mínimo de $0,4 \mathrm{~mL}$ de sangue por peixe. O sangue foi transferido das seringas para tubos de ensaio que foram centrifugados a uma velocidade de 3500rpm por cinco minutos. Retirou-se o plasma das amostras que foi centrifugado novamente à mesma velocidade e tempo para eliminação total de resíduos dos plasmas provenientes das amostras.

Após as coletas de sangue os peixes utilizados foram abatidos (cinco juvenis com 32 dias e cinco juvenis com 64 dias, de cada unidade experimental) através de choque térmico, acondicionados em sacolas plásticas devidamente identificadas e levados ao freezer para congelamento. Após o término do experimento, os peixes foram descongelados e as escamas e as vísceras foram retiradas. As carcaças 
foram pesadas, trituradas com processador industrial de pequeno porte e pesadas novamente. A massa obtida foi congelada e, após 24 horas de congelamento, foi levada ao liofilizador para retirada da umidade.

Passado um período de 48 horas as amostras foram pesadas em balança digital com precisão de 0,1 e moídas no moinho de bola. Após o processamento das amostras foram feitas análises através da adaptação da metodologia descrita por SILVA \& QUEIROZ (2000) para análise de extrato etéreo, proteína bruta, matéria mineral. Foram quantificados também o extrato não nitrogenado, além de matéria seca, teor de unidade das amostras e glicemia sanguínea.

Todas as análises foram feitas no Laboratório de Zootecnia e Nutrição Animal (LZNA) da UENFCCTA. Com os valores obtidos nas análises anteriores foram calculados os valores de eficiência de retenção de proteína bruta (ERPB) e taxa de eficiência protéica (TEP).

Para a análise estatística do experimento foi utilizado o programa estatístico SAEG versão 9.1. Foram feitas análise de variância, regressões lineares simples e múltiplas e correlações de Pearson, com os dados obtidos através das análises feitas no LZNA.

\section{RESULTADOS E DISCUSSÃO}

Os valores dos parâmetros relacionados à qualidade da água, oxigênio dissolvido $\left(\mathrm{O}_{2} \mathrm{D}\right)$, temperatura $\left(\mathrm{T}^{\circ} \mathrm{C}\right), \mathrm{pH}$ e condutividade elétrica (COND.), mensurados durante o período experimental, estão na Tabela 1 .
Tabela 1. Valores médios dos parâmetros físicoquímicos da água no experimento

\begin{tabular}{lccccc}
\hline \multirow{2}{*}{ Parâmetros } & \multicolumn{5}{c}{ Tratamento (hL) } \\
\cline { 2 - 6 } & & $\mathbf{6}$ & $\mathbf{1 2}$ & $\mathbf{1 8}$ & $\mathbf{2 4}$ \\
\hline Oxigênio Dissolvido (mg/L) & & 5,9 & 5,8 & 5,6 & 5,7 \\
$\mathrm{pH}$ & & 6,17 & 6,08 & 5,72 & 5,76 \\
Condutividade Elétrica (uS) & & 366 & 396 & 543 & 561 \\
Temperatura ("C) & $\mathrm{M}$ & 29,5 & 29,8 & 29,1 & 29,4 \\
& $\mathrm{~T}$ & 29 & 28,9 & 28,6 & 28,7 \\
\hline
\end{tabular}

Durante o período experimental, o teor médio de oxigênio dissolvido foi de $5,75 \mathrm{mg} / \mathrm{L}$. Segundo ARAUJO-LIMA \& GOMES (2005), o tambaqui tem seu crescimento normal em níveis de oxigênio acima de $3,0 \mathrm{mg} / \mathrm{L}$; portanto, os valores de oxigênio dissolvido obtidos no experimento ora descrito atendem perfeitamente à exigência do tambaqui. Da mesma forma, a média do $\mathrm{pH}$ manteve-se dentro dos padrões recomendados por ARIDE et al. (2004), entre 4,0 e 6,5. A temperatura dos aquários experimentais mostrou-se adequada para espécies de clima tropical, apresentando médias $29,45^{\circ} \mathrm{C}$ pela manhã e $28,8^{\circ} \mathrm{C}$ pela tarde.

Os valores de condutividade elétrica da água também se mantiveram dentro de faixas ideais para o cultivo de peixes tropicais. Tais valores estão bem próximos ao encontrados por POLESE et al. (2010) trabalhando com alevinos de pacu (Piaractus mesopotamicus). Os maiores valores encontrados desse parâmetro provavelmente esta associado a presença de íons de cálcio na água de abastecimento das unidades experimentais. O que permite afirmar que esses parâmetros de qualidade da água não interferem nos resultados do presente.

Tabela 2. Composição bromatológica da matéria seca na carcaça eviscerada e escamada de juvenis de tambaqui submetidos a diferentes fotoperíodos no início, no $32^{\circ}$ e no $64^{\circ}$ dia de experimento

\begin{tabular}{lccccccccc}
\hline \multirow{2}{*}{ Variáveis } & \multicolumn{8}{c}{ Tratamentos } \\
\cline { 2 - 10 } & \multicolumn{1}{c}{6} & \multicolumn{7}{c}{12} & \multicolumn{3}{c}{18} & \multicolumn{2}{c}{24} \\
\cline { 2 - 9 } & inicio & $32^{\circ}$ & $64^{\circ}$ & $32^{\circ}$ & $64^{\circ}$ & $32^{\circ}$ & $64^{\circ}$ & $32^{\circ}$ & $64^{\circ}$ \\
\hline MS (\%) & 28,58 & 29,63 & 32,79 & 28,99 & 33,37 & 27,78 & 32,7 & 29,23 & 33,1 \\
PB (\%) & 64,97 & 48,78 & 44,51 & 49,42 & 44,27 & 51,85 & 43,12 & 49,64 & 43,04 \\
EE (\%) & 10,35 & 32,06 & 36,12 & 31,36 & 36,12 & 27,59 & 36,72 & 30,65 & 35,66 \\
MM (\%) & 13,42 & 14,06 & 15,21 & 13,94 & 14,89 & 14,71 & 14,73 & 13,88 & 15,08 \\
ENN (\%) & 11,26 & 5,11 & 4,16 & 5,28 & 4,72 & 5,85 & 5,44 & 5,83 & 6,22 \\
\hline
\end{tabular}

$(\mathrm{MS} \%)$ - porcentagem de matéria seca na carcaça, (PB \%) - porcentagem de proteína bruta na carcaça, (EE \%) - porcentagem extrato etéreo na carcaça, $(\mathrm{MM} \%)$ - porcentagem da matéria mineral na carcaça e (ENN \%) - porcentagem de extrato não nitrogenado na carcaça. 
Os resultados observados no experimento quanto à composição bromatológica da carcaça de juvenis de tambaqui indicaram uma tendência ao aumento da porcentagem de gordura na carcaça em detrimento da porcentagem de proteína em relação aos valores alcançados no inicio e ao final do período experimental.

Os valores de proteína bruta encontrados neste trabalho, apesar de diminuírem entre o inicio e o fim, estão próximos aos resultados que TERRAZAS et al. (2002) encontraram quando trabalharam com peixes da mesma espécie e obtiveram valores de 44,08 a 45,65\% de PB na carcaça dos juvenis. Pôdese verificar um aumento na porcentagem de proteína bruta quando se consideraram trabalhos que só avaliaram a composição bromatológica do filé, como o de LANNA et al. (2004), que apresentou valor de proteína bruta média igual a $87,86 \%$ na matéria seca do filé de juvenis de tilápia do Nilo, e o de SANTOS et al. (2000) e SANTOS et al. (2001) que, trabalhando com filé de trairão (Hoplias lacerdae), obtiveram valores de proteína bruta na matéria seca em torno de $81,34 \%$. Independente da variação no trabalho, ambos obtiveram valores finais bem superiores aos encontrados no presente estudo.

Os menores valores de proteína bruta encontrados neste trabalho devem-se ao fato de que ao analisar uma carcaça estamos analisando um conjunto de tecidos (tecido ósseo, cartilaginoso, muscular entre outros) e a análise desse conjunto de tecidos resulta numa menor parte ou porcentagem de proteína bruta ao final.

Pôde-se perceber o inverso em relação ao extrato etéreo, pois neste trabalho verificou-se valores maiores que os obtidos por SANTOS et al. (2006), que encontraram valores de 5,81 para matéria seca e 1,21 na matéria natural, MACEDO-VIEGAS et al. (2002) que trabalharam com trutas e obtiveram valores de 7,34 a 5,41\% e CAULA et al. (2008) que analisaram o filé de diferentes espécies de pescados e encontraram valores entre 1,0 e 4,6. Entretanto, ao se compararem os resultados obtidos neste trabalho com outros que analisaram a carcaça dos peixes constatar-se-á que os valores estão bem próximos como verificados por TERRAZAS et al (2003), que obtiveram valores variando entre 40,67 a 44,75, MARENGONI \& SANTOS (2006), que avaliaram tilapias provenientes de pesque-pague diferentes, obtendo um resultado entre 30,68 a $35,65 \%$ para os machos e 20,90 a 38,59 para as fêmeas, e ITUASSÚ et al. (2004), que, trabalhando com restrição alimentar de tambaqui, encontraram valores de proteína bruta na matéria seca da carcaça num intervalo de 55,50 até $58,73 \%$, e de extrato etéreo num intervalo de 19,50 a $23,37 \%$.

Pôde-se notar também a modificação entre os valores obtidos no inicio e no final do trabalho para as variáveis bromatológicas. Essa diferença deve-se ao crescimento do animal e, possivelmente, à ração que não é especifica para a espécie, causando um acúmulo de gordura na carcaça, devido ao desequilíbrio protéico:energético e, consequentemente, a uma redução na proteína e aumento na gordura, que não está relacionada ou não sofre influência dos diferentes tratamentos, uma vez que a análise estatística não demonstrou diferença significativa entre os tratamentos.

$\mathrm{Na}$ Tabela 4 estão os valores de glicemia sanguínea, os valores da taxa de eficiência protéica (TEP) e a taxa de retenção de proteína bruta (ERPB). Essas taxas utilizam valores obtidos na biometria e na análise bromatológica e transformados em dados para avaliação e quantificação do uso do nitrogênio fornecido na dieta correlacionado com a produção de proteína do animal.

As variáveis da Tabela 3 não apresentaram equações de regressão com grau de significância confiável. No entanto, os valores obtidos neste experimento para essas mesmas variáveis são próximos dos valores obtidos em outros experimentos, como em trabalho realizado por MUÑOZ-RAMÍREZ \& CARNEIRO (2002), que obtiveram valores de TEP variando entre 2,27 e $1,76 \%$, enquanto que para a ERPB os valores entre 29,81 e 38,56.

Tabela 3. Valores médios da taxa de eficiência protéica (TEP), da eficiência de retenção de proteína bruta (ERPB) e dos níveis de glicemia mensurados

Tratamentos

\begin{tabular}{lccccccccc}
\cline { 2 - 9 } \multicolumn{1}{c}{ Variáveis } & \multicolumn{2}{c}{$6 \mathrm{~h}$} & \multicolumn{2}{c}{$12 \mathrm{~h}$} & \multicolumn{2}{c}{$18 \mathrm{~h}$} & \multicolumn{2}{c}{$24 \mathrm{~h}$} \\
\cline { 2 - 10 } & 32 & 64 & 32 & 64 & 32 & 64 & 32 & 64 \\
\hline ERPB (\%) & 34 & 27,2 & 35 & 28,5 & 34,3 & 26,6 & 39,1 & 24,3 \\
TEP (\%) & 1,54 & 2,01 & 1,57 & 2,02 & 1,57 & 1,98 & 1,45 & 1,83 \\
Glicemia (mg/dL) & 98,75 & 129,63 & 80,15 & 143 & 72,3 & 111 & 64,78 & 100,13 \\
\hline
\end{tabular}


Já LANNA et al. (2004) obtiveram valores maiores que os estabelecidos neste trabalho para taxa de eficiência protéica (TEP), entre 3,29 e 4,37g, quando trabalharam com juvenis de tilápia, utilizando diferentes fontes de óleos e fibras na dieta. FERNANDES et al. (2001), trabalhando com diferentes níveis de proteína para alevinos de pacu (Piaractus mesopotamicus), encontraram valores da TEP iguais a 3,23, 3,13 e 2,92\% para os respectivos valores de $\mathrm{PB}$ na ração 22,26 e $30 \%$.

Esses valores menores de TEP encontrados no presente trabalho podem estar relacionados com o estresse quantificado de forma leve na primeira coleta de sangue para os peixes que permaneceram em fotoperíodos maiores. Entretanto, o resultado da segunda coleta já indicou altos valores de glicose sanguínea, o que pode caracterizar animais estressados, para todos os tratamentos.

Quando o peixe encontra-se numa situação desfavorável, o nível de glicose sanguínea aumenta, como demonstrado por MARTINS et al. (2002), que submeteram o híbrido tambacu a estímulos consecutivos de estresse. Esses autores observaram um valor inicial de glicose sanguínea igual a 71,00 $\mathrm{mg} / \mathrm{dL}$ no tempo zero chegando a alcançar valores de glicose sanguínea igual a 148,35 mg/dL após duas horas de estímulos, demonstrando um estresse agudo.

BRANDÃO et al. (2004) quantificaram o nível de glicose sanguínea de tambaquis durante um experimento de densidade obtendo valores de glicose sanguínea entre 51 a $65 \mathrm{mg} / \mathrm{dL}$. Esses resultados não demonstram sinais de estresse com relação às densidades usadas no trabalho.

CHAGAS et al. (2002), testando as densidades de estocagem de tambaqui, apresentaram os seguintes valores de glicose sanguínea, 61,80; 67,30 e $63,67 \mathrm{mg} / \mathrm{dL}$ para as respectivas densidades de estocagem 25; 50 e 75 peixes/ $\mathrm{m}^{3}$, não demonstrando a presença de fatores estressantes durante o experimento, uma vez que esses valores estão dentro da faixa estipulada para os valores de glicose sanguínea da espécie.

GOMES et al. (2001) quantificaram os valores de glicose sanguínea para os juvenis de tambaqui em situação de repouso chegando a valores entre 50 a $70 \mathrm{mg} / \mathrm{dL}$, valores estes próximos aos obtidos nos maiores fotoperíodos do experimento ora descrito (18 e 24 horas de luz), indicando que não houve estresse nesses tratamentos até os 32 dias.

O estresse demonstrado pelo nível de glicose sanguínea pode explicar os valores baixos encontrados para a TEP e a ERPB, pois o estresse diminui a eficiência do metabolismo, aumenta a taxa de passagem do alimento, diminui o tempo de digestão da dieta, prejudicando a utilização do alimento para o desenvolvimento do animal.

Tabela 4. Matriz para correlação de Pearson para as variáveis glicose sanguínea (GLIC), eficiência de retenção de proteína bruta (ERPB), extrato etéreo na matéria seca (EEMS), proteína bruta na matéria seca (PBMS), proteína bruta na matéria natural (PBMN), cinzas na matéria natural (MMMN) e extrato não nitrogenado na matéria seca (ENNMS) no trabalho

\begin{tabular}{cccc}
\hline Variável & Vaniável & Correlação & Significância \\
\hline GLIC & ENNMS & -0.6688 & 0.0023 \\
& ENNMN & -0.6665 & 0.0024 \\
ERPB & TEP & 0.8498 & 0.0001 \\
EEMS & PBMS & -0.8679 & 0.0001 \\
& PBMN & -0.8548 & 0.0001 \\
PBMS & TEP & -0.2935 & 0.1350 \\
& EEMN & -0.8656 & 0.0001 \\
PBMN & EEMS & -0.8548 & 0.0001 \\
& EEMN & -0.8003 & 0.0001 \\
MMMN & ENNMS & -0.6320 & 0.0043 \\
& ENMMN & -0.6115 & 0.0059 \\
ENNMS & MMMS & -0.6911 & 0.0015 \\
& MMMN & -0.6320 & 0.0043 \\
\hline
\end{tabular}

Observa-se por meio dos valores encontrados na correlação entre PB e EE que essas variáveis têm sentidos opostos na composição bromatológica das carcaças avaliadas durante o experimento, sendo que, quanto maior for a percentagem de uma variável na carcaça, menor será a outra. Entretanto, não foram observadas correlações entre a $\mathrm{PB} \mathrm{e}$ outras variáveis analisadas bromatologicamente, como PB e MM, PB e MS e PB e ENN.

No entanto, foi observada uma correlação negativa e superior a $60 \%$ entre a glicose sanguínea e o extrato não nitrogenado da carcaça. É de se esperar uma correlação entre as duas variáveis, uma vez que nos peixes, segundo SILVEIRA et al. (2009), assim como ocorre com os mamíferos, a principal fonte energética do corpo é a glicose. Quando ocorre um excesso de glicose sanguínea, ela é transformada em glicogênio, sendo armazenada no fígado e nos músculos. Para manter a homeostase energética durante um período de estresse (privação de alimento, disputa territorial, fuga, entre outros), o 
glicogênio é mobilizado e transformado em glicose, sendo mantidos os valores da glicemia sanguínea, evitando, assim, a falta de energia para as células do corpo do animal (SILVEIRA et al;. 2009).

$\mathrm{Na}$ situação de estresse percebida no experimento, através dos níveis de glicose sanguínea dos juvenis, pode-se dizer que o metabolismo provavelmente foi prejudicado e, consequentemente, a manutenção do glicogênio das reservas metabólicas dos juvenis foi acionada, fazendo com que a glicemia sanguínea aumentasse, confirmando a existência da correlação inversa entre os fatores de glicemia e extrato não nitrogenado na carcaça.

\section{CONCLUSÕES}

A composição bromatológica dos juvenis de tambaqui (Colossoma macropomum), a taxa de eficiência protéica e a taxa de eficiência de retenção de proteína bruta não foram afetadas pelo fotoperíodo emeral durante o período experimental.

\section{REFERÊNCIAS}

ARIDE, P.H.R., ROUBACH, R. E VAL, A.L. (2004), Water $\mathrm{pH}$ in central Amazon and its importance for tambaqui (Colossoma macropomum) culture. World Aquaculture. Baton Rouge, v.35, p.24-27.

BEZERRA, K,S., SANTOS, A.J.G., LEITE, M.R., SILVA, A.M., LIMA, M.R., Crescimento e sobrevivência da tilápia chitralada submetida a diferentes fotoperíodos. Pesquisa Agropecuaria Brasileira, Brasilia, v. 43, n. 6, p.737-743, jun, 2008

BRANDÃO, F.,R. GOMES, L.C., CHAGAS, E.C., ARAUJO, L.D. Densidade de estocagem de juvenis de tambaqui durante a recria em tanque-rede. Pesquisa Agropecuaria Brasileira, Brasília, v.39, p.357-362, 2004

BROMAGE, N.; PORTER, M.; RANDALL, C. The environmental regulation of maturation in farmed finfish with special reference to the role of photoperiod and melatonin. Aquaculture, v.197, p.63-98, 2001

CAULA, F.C.B., OLIVEIRA, M.P., MAIA, E.L. Teor de colesterol e composição centesimal de algumas espécies de peixes do estado do Ceará. Ciência. Tecnologia de Alimentos, Campinas, v. 28, n.4, p. 959-963, out.-dez, 2008

CHAGAS, E.C.; LOURENÇA, J.N.P.; VAL, A.L. Desempenho e estado de saúde de tambaquis cultivados em tanques-rede sob diferentes densidades de estocagem. Anais do Simpósio Brasileiro de Aqüicultura - Aquabio, Goiânia, GO, Brasil. p.83-93, 2002
CONTRERAS-GUZMÁN, E.S. Bioquímica de pescados e derivados. 1. ed. Jaboticabal: ed. FUNEP. 1994, 409p,

CRESCENCIO, R. Ictiofauna brasileira e seu potencial para criação. In: BALDISSEROTTO, B.; GONES, L.C. (ed). Espécies nativas para piscicultura no Brasil. $1^{\mathrm{a}}$ ed., Santa Maria. Ed. da UFSM, 2005, p. 23-33.

FAO from Brasil: Banco de dados. Anuários de Estadísticas de pesca Cuadros resumidos. Disponivel em: ftp://ftp.fao.org/fi/stat/summary/inicio.htm. acesso 2010.

FERNANDES, J. B. K., CARNEIRO, D. J., SAKOMURA, N. K.; Fontes e Níveis de Proteína Bruta em Dietas para Alevinos de Pacu (Piaractus mesopotamicus). Revista Brasileira. de Zootecnia, v.29, p. 646-653, 2001.

GARDUÑO-LUGO, M., GRANADOS-ALVARES, I., OLVERA-NOVOA, M.A. MUÑOZ-CÓRDOVA, G. Comparison of growth, fillet yield and proximate composition between Stirling nile tilapia (wild type) (Oreochromis niloticus, Linnaeus) and red hybrid tilapia (Florida red tilapia X Stirling red O. niloticus) males. Aquaculture Research, v.34, p. 1023-1028, 2003.

GOMES, L.C.; CHIPIRI-GOMES, A.R.; LOPES N.P.; ROUBACH, R.; ARAÚJO-LIMA, C.A.R.M. Efficacy of benzocaine as anesthesic for tambaui juveniles (Colossoma macropomum). Journal of the World Aquaculture Society, v.31, p. 426-431, 2001.

GURGEL, J.J.S., FREITAS, J.V.F. Sobre a composição química de doze espécies de peixes de valor comercial de açudes do nordeste brasileiro. Boletim Técnico DNOCS, v.30, p. $45-57,1972$.

HUSS, R.B. El pescado fresco su calidad y cambios de su calidad. Roma: FAO, 1998. 202 p. (Documento Técnico de Pesca, 348).

KUBITZA, F. Tilápia - Tecnologia e planejamento na produção comercial. 1. ed. São Paulo, 2000, p. 285.

ITUASSÚ, D.R.; SANTOS G.R.S.; ROUBACH, R.; PEREIRA-FILHO, M. Níveis de proteína bruta para juvenis de pirarucu. Pesquisa Agropecuaria Brasileira. Brasília, v.40, p. $255-259,2004$.

LANNA, E.A.T., PEZZATO, L.E., FURUYA, W.M., VICENTINI,C.A., CECON, P.R., BARROS, M.M., Fibra bruta e óleo em dietas práticas para alevinos de tilápia do nilo (Oreochromis niloticus). Revista Brasileira. de Zootecnia, v.33, n.6, p.2177-2185, 2004.

MACEDO-VIEGAS, E.M.; SOUZA, M.L.R.; ZUANON, J.A.S.; FARIA, R.H.S Rendimento e composição centesimal de filés in natura e pré-cozidoem truta arco-íris, Oncorhynchus mykiss (Wallbaum). Acta Scientiarum, Maringá, v. 24, n. 4, p. 1191-1195, 2002.

MARENGONI, N.G e SANTOS R.S. Rendimento e composição de filés de tilápia do nilo (Oreochromis niloticus) e piavuçu (Leporinus macrocephalus) cultivados em pesque-pagues. Archivos de Zootecnia. Cordoba, v. 55 p. $227-238,2006$. 
MARTINS, M. L.; MORAES, F.R.; FUJIMOTO, R.Y.; NOMURA, D.T.; FENERICK JR, J. Resposta do hibrido tambacu (Piaractus mesopotamicus Homberg, 1887 macho X Colossoma macropomum Cuvier, 1818 femea) a estímulos simples e consecutivos de captura. Boletim do Instituto de Pesca, São Paulo, v. 28. p. 195 - 204, 2002.

MUÑOZ-RAMIREZ A.P.; CARNEIRO D.J., Suplementação de lisina e metionina em dietas com baixos níveis protéicos para o crescimento inicial do pacu, Piaractus mesopotamicus (Holmberg). Acta Scientiarum, v.24, p. 909-916, 2002.

OETTERER, M. Industrialização de pescado cultivado. $1^{\text {a }}$ ed. Guaíba: ed. Agropecuária, 2002, 200 p.

POLESE, M.F.; VIDAL JUNIOR, M.V.; MENDONÇA, P.P.; TONINI, W.C.T.; RADEL, M.C.; ANDRADE, D.R (2010). Efeito da granulometria do milho no desempenho de juvenis de pacu, Piaractus mesopotamicus (Holmberg, 1887). Arquivo Brasileiro de Medicina Veterinária e Zootecnia, v.62, n.6, p.1469-1477.

REYNALTE-TATAJE, D.; LUZ, R.K.; MEURER, S.;ZANIBONI-FILHO, E.; NUÑER, A.P.O. Influência do fotoperíodo no crescimento e sobrevivência de pós-larvas de piracanjuba Brycon orbignyanus (Valenciennes, 1849) (Osteichthyes, Characidae). Acta Scientiarum, v.24, p.439-443, 2002.

SANTOS;A.B., GINAR R.M.B., GALARÇA R.C.G.,
NETO J.B. Composição bromatológica do filé da palometa (Serrasalmus spilopleura Kner, 1860) na região de Uruguaiana-RS/Brasil. Revista da Faculdade de ZootecniaVeterinária e Agronomia, Uruguaiana, v.13, n.2, p. 166-170, 2006.

SANTOS, B. A., MELO, J.F.B., LOPES, P.R.S., MALGARIM, M.B. Composição química e rendimento do file da traira (Hoplias malabaricus). Revista Faculdade de Zootecnia, Veterinária e Agronomia. v.7/8, p. 33-39, 2000-2001.

SILVEIRA, U.S.; LOGATO, P.V.R; PONTES E.C. Utilização e metabolismo dos carboidratos em peixes. Revista Eletrônica Nutritime, v.6, $\mathrm{n}^{\circ}$ 1, p.817-836, 2009. disponível em http://www.nutritime.com.br/ arquivos_internos/artigos/079V6N1P817_836_JAN2009 .pdf

TAVARES-DIAS, M., MARTINS, M.L, SCHALCH, S.H.C., ONAKA, E.M., QUINTANA, C.I.F., MORAES,J.R.E., MORAES, F.R. . Fauna parasitaria de peixes iriundos de "pesque-pague" do município de Franca, São Paulo, Brasil. II. Metazoários. Revista Brasileira de Zoologia, Curitiba, v.18, p. 81-95, 2001.

TERRAZAS, W.D.M.; PEREIRA-FILHO, M.; OLIVEIRA-PEREIRA, M.I. Efeito da farinha de residuo de peixe e de frango no desempenho e na composição corporal de juvenis de tambaqui, Colossoma macropomum (Cuvier, 1818). Acta Amazonica, v.31, p.155-162, 2002. 